(2)

\title{
Nebulized formoterol: a review of clinical efficacy and safety in COPD
}

This article was published in the following Dove Press journal:

International Journal of Chronic Obstructive Pulmonary Disease

25 June 2010

Number of times this article has been viewed

\author{
Nicholas J Gross' \\ James F Donohue ${ }^{2}$ \\ 'Hines VA Hospital, Stritch Loyola \\ School of Medicine, Hines, IL, USA; \\ ${ }^{2}$ University of North Carolina School \\ of Medicine, Chapel Hill, NC, USA
}

Correspondence: Nicholas J Gross Hines VA Hospital, Stritch Loyola School of Medicine, Pulmonary and Critical Care Division, Hines, IL 60I4I USA

Tel + I 3129539498

Email grossnicholasI@gmail.com
Abstract: A nebulized formulation of formoterol, Perforomist ${ }^{\circledR}, 20 \mu \mathrm{g} / 2 \mathrm{ml}$, has been available since 2007 for the maintenance treatment of chronic obstructive pulmonary disease (COPD). We review the safety and efficacy data obtained during its development. In a dose-finding study, formoterol inhalation solution (FFIS) was similar to the formoterol originator, Foradil ${ }^{\circledR}$ $12 \mu \mathrm{g}$ DPI (FA) in patients with COPD. In a 12-week efficacy study, FFIS manifested a rapid onset of action and $\mathrm{FEV}_{1}$ peak, $\mathrm{AUC}_{0-12}$, and trough levels similar to FA. No loss of efficacy, tachyphylaxis, was observed over 12 weeks of regular administration. In placebo-controlled studies in COPD patients receiving maintenance tiotropium, the addition of FFIS significantly augmented bronchodilation over the 6-week treatment duration, signifying that nebulized formoterol can further improve lung function in patients who are receiving tiotropium without an observed increase in adverse reactions. The safety profile of FFIS during 12-week and 1 -year studies revealed adverse events that were similar to those of placebo and FA. Cardiac rhythm studies, including frequent ECGs and Holter monitoring, did not indicate any increase in rate or rhythm disturbances greater than placebo or FA. We conclude that maintenance use of Perforomist ${ }^{\circledR}$ is appropriate for patients with COPD who require or prefer a nebulizer for management of their disease.

Keywords: long-acting bronchodilator, $\beta$-agonist, chronic bronchitis, pulmonary emphysema, Perforomist $^{\mathbb{R}}$, chronic obstructive pulmonary disease

Readers of this journal will be well aware of the burden of chronic obstructive pulmonary disease (COPD) on patients, society, and the health care system. In the absence of disease modifying medications, our main efforts are directed to smoking cessation, symptom relief, and improvements in the health status of patients. To this end, the Global Initiative for Chronic Obstructive Lung Disease (GOLD) has made recommendations concerning bronchodilator choices for each stage of disease severity. ${ }^{1}$ In COPD from moderate through to more severe stages of the disease, "regular treatment with long-acting bronchodilators is more effective and convenient than with short-acting agents". In the United States, three long-acting bronchodilators are currently available and approved for the maintenance treatment of COPD; one is an anticholinergic agent (tiotropium) and two are beta-adrenergic agents (formoterol and salmeterol). Of these, formoterol has the unique properties of being a 'full' agonist and with an onset of action that is as rapid as any other beta-adrenergic agent including albuterol. ${ }^{2}$ It also provides a full 12-hour duration of action, with a potency of bronchodilation that equals or exceeds that of all other bronchodilators, and an excellent safety profile in COPD patients, particularly when used in the moderate dosages that are approved in the United States. ${ }^{3}$ 
To obtain the greatest utility from the available long-acting agents, they have to meet the needs of the diverse COPD population. Inhalation is the preferred route of administration; medication can be delivered in many ways (for example, dry powders [DPIs], pressurized metered dose inhalers [pMDIs]) but for a substantial proportion of the COPD population, nebulization is the preferred route., ${ }^{4,5}$ This may be because the patient has difficulty using another method properly due, for example, to poor motor coordination, poor manual dexterity, arthritis involving the hands, neurological problems such as a stroke or Parkinson's disease, or poor eyesight or mental capacity. For the mostly older COPD population, who typically has one or more of these comorbidities, such limitations are not uncommon. There are also patients who have a personal preference for nebulizer treatment or feel it provides them with a better outcome than a DPI or MDI. Results of studies in which the efficacy of various delivery methods is compared, as reviewed by Dolovich and colleagues for a consortium of Pulmonary and Allergy Societies, ${ }^{5}$ have not shown an advantage for any other delivery method over nebulization. Among the longacting agents, formoterol is the only bronchodilator that is available in a nebulizer formulation. Two such formulations were approved in 2007, arformoterol, a single enantiomer of formoterol marketed as Brovana ${ }^{\circledR}$, and racemic formoterol, marketed as Perforomist ${ }^{\circledR}$. In the present report the properties of Perforomist ${ }^{\circledR}$, the published information concerning its efficacy and safety, and recommendations for its use in the maintenance care of COPD are reviewed.

Seven studies were conducted as part of the clinical program for Perforomist ${ }^{\mathbb{}}$ (Table 1) ranging from Phase II single-dose dose-ranging studies to Phase IV comparator and add-on studies in which a total of 1374 patients were enrolled. All studies were randomized, controlled multicenter studies conducted at sites throughout the United States.

\section{Pharmacokinetics and pharmacodynamics}

A single-dose 7-way crossover study was conducted to establish the dose of nebulized formoterol (FFIS) comparable to the formoterol DPI product marketed in the United States $\left(12 \mu \mathrm{g}\right.$ Foradil $\left.^{\circledR}, \mathrm{FA}\right)$ by determining the bronchodilatory response in COPD patients to a single nebulized dose of FFIS at various doses $(2.5,5,10,20$, and $40 \mu \mathrm{g})$, FA, or placebo. ${ }^{6}$ Treatment with FFIS $40 \mu \mathrm{g}$ produced significantly higher bronchodilation than FA when the primary efficacy variable, $\mathrm{FEV}_{1} \mathrm{AUC}_{0-12}$, was compared, and FFIS $20 \mu \mathrm{g}$ was the dose determined to be comparable to FA. Secondary efficacy endpoints, such as $\mathrm{FEV}_{1}$ by timepoint, peak $\mathrm{FEV}_{1}$, and trough $\mathrm{FEV}_{1}$ supported the comparability

Table I Clinical studies of nebulized formoterol (FFIS) in COPD

\begin{tabular}{|c|c|c|c|c|}
\hline Reference & Objective & Design* & Treatments $^{\dagger}$ & \# Pts \\
\hline \multirow[t]{6}{*}{ Gross et al $2008^{6}$} & Dose selection & $\mathrm{SD}, \mathrm{DB}, \mathrm{DD}, \mathrm{XO}$ & $2.5 \mu \mathrm{g}$ FFIS & 47 \\
\hline & & & $5.0 \mu \mathrm{g}$ FFIS & 47 \\
\hline & & & $10 \mu \mathrm{g}$ FFIS & 47 \\
\hline & & & $20 \mu \mathrm{g}$ FFIS & 47 \\
\hline & & & $40 \mu \mathrm{g}$ FFIS & 47 \\
\hline & & & Placebo & 47 \\
\hline \multirow[t]{4}{*}{ Gross et al $2008^{6}$} & Pharmacokinetics & $\mathrm{SD}, \mathrm{OL}, \mathrm{XO}$ & $10 \mu \mathrm{g}$ FFIS & 12 \\
\hline & & & $20 \mu \mathrm{g}$ FFIS & 12 \\
\hline & & & $244 \mu \mathrm{g}$ FFIS & 13 \\
\hline & & & $\mathrm{FA}$ & 12 \\
\hline Gross et al $2008 a^{14}$ & Efficacy and safety & I2-wk, DB, DD, PG & FFIS & 123 \\
\hline \multirow[t]{2}{*}{ Nelson et al $2007^{25}$} & & & FA & 114 \\
\hline & & & Placebo & 114 \\
\hline \multirow[t]{2}{*}{ Sutherland et al $2009^{7}$} & Active comparison & 2-wk, OL, XO & FFIS & 109 \\
\hline & & & IPR/ALB & 109 \\
\hline \multirow[t]{2}{*}{ Donohue et al $2008^{26}$} & Long-term safety & 52-wk, OL, PG & FFIS & 463 \\
\hline & & & FA & 106 \\
\hline Tashkin et al $2008^{35}$ & Add-on tiotropium & 6-wk, DB, PG, PC & $\mathrm{TIO}+\mathrm{FFIS}$ & 67 \\
\hline Tashkin et al $2009^{37}$ & & & TIO + placebo & 63 \\
\hline Hanania et al $2009^{36}$ & Add-on tiotropium & 6-wk, DB, PG, PC & $\mathrm{TIO}+\mathrm{FFIS}$ & 78 \\
\hline Tashkin et al $2009^{37}$ & & & TIO + placebo & 77 \\
\hline
\end{tabular}

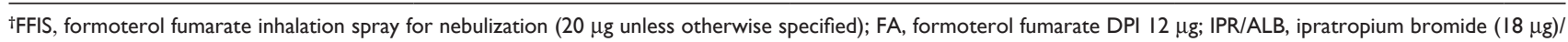
albuterol sulfate (I03 $\mu \mathrm{g}$ ) MDI; TIO, tiotropium bromide $18 \mu \mathrm{g}$.

Abbreviations: SD, single dose; DB,double blind; XO, crossover; PG, parallel group; DD, double dummy; PC, placebo controlled. 
of FFIS $20 \mu \mathrm{g}$ and FA. Mean $\mathrm{FEV}_{1} \mathrm{AUC}_{0-12}$ increased by $2.3 \mathrm{~L} /$ hour after either FFIS or FA treatment compared with a slight decrease after placebo. The percentage of patients that responded to treatment with $\geq 15 \%$ increase in bronchodilation was dose-dependent, with $72.3 \%$ responders after FFIS $20 \mu \mathrm{g}$ compared with $85.1 \%$ after FA. Time to onset of bronchodilation was more rapid after FFIS $20 \mu \mathrm{g}$ (3.9 minutes) than after FA (13.5 minutes). The duration of action of FFIS was comparable to that of FA, given that FEV at 12 hours post-dose (trough $\mathrm{FEV}_{1}$ ) was $9 \%$ above pre-dose levels in both groups. A crossover study of twice-daily FFIS versus four-times-daily ipratropium-albuterol combination treatment (IPR-ALB) confirmed the 12-hour duration of bronchodilation, demonstrating that trough $\mathrm{FEV}_{1}$ improved from baseline to Day 14 with FFIS but not IPR-ALB. ${ }^{7}$

A pharmacokinetic study confirmed the comparability of FFIS $20 \mu \mathrm{g}$ and FA by urine pharmacokinetics. ${ }^{6}$ Blood and urine samples for $\mathrm{PK}$ analysis were taken pre-dose after which nebulized FFIS (10 $\mu \mathrm{g}, 20 \mu \mathrm{g}$, or $244 \mu \mathrm{g})$ or FA $12 \mu \mathrm{g}$ was administered. The mean amount of drug excreted unchanged in 24-hour urine by those receiving FFIS $20 \mu \mathrm{g}$ and FA was $349.6 \pm 190.3$ and $406.3 \pm 116.5$, respectively, compared with $109.7 \pm 56.0$ for FFIS $10 \mu \mathrm{g}$ and $3317.5 \pm 1733.0$ for FFIS $244 \mu \mathrm{g}$. At the time of the study, plasma formoterol fumarate levels could only be reliably measured following treatment with FFIS $244 \mu \mathrm{g}$, as concentrations following the other treatments were below the lower level of quantification $(2.5 \mathrm{pg} / \mathrm{mL})$, a problem previously observed with the DPI product. $^{8}$

There were no clinically significant changes in clinical laboratory measures, with the exception of dose-dependent decreases in mean serum potassium ranging from -0.23 to $-0.68 \mathrm{mEq} / \mathrm{L}$ over the 24 hour period following dosing with FFIS $20 \mu \mathrm{g}$, FFIS $244 \mu \mathrm{g}$, and FA and increases in mean serum glucose at 1 hour post-dose with all treatments. There were no clinically significant changes in ECG evaluations other than a few minor shifts from baseline in P-R intervals and no differences in responses to treatment. Mean heart rate rose in the first 6 hours after FFIS $244 \mu \mathrm{g}$ dosing. ${ }^{6}$

As previously shown with other formoterol formulations, these results with nebulized formoterol demonstrated: 1) a rapid onset of bronchodilation, ${ }^{2,9}$ 2) linear kinetics and dose proportionality in both pulmonary and nonpulmonary measures, ${ }^{8,10-12}$ and 3) a linear relationship between urinary formoterol excretion and changes in serum potassium, serum glucose, and heart rate. ${ }^{13}$ Taken together, these results provided the dose selection and dose tolerance data necessary for further clinical development of the nebulized product at the $20 \mu \mathrm{g}$ dose.

\section{Efficacy}

The efficacy of nebulized formoterol was first established when FFIS $20 \mu \mathrm{g}$ was compared to marketed formoterol DPI (Foradil ${ }^{\circledR} 12 \mu \mathrm{g}, \mathrm{FA}$ ) and placebo for 12 weeks in a randomized, double-blind, double-dummy trial. The primary outcome, $\mathrm{FEV}_{1} \mathrm{AUC}_{0-12}$ at week 12 , was significantly improved by $185 \mathrm{~mL}$ with FFIS treatment compared with placebo $(P<0.0001) .{ }^{14}$ The improvements in bronchodilation were observed starting on Day 1 of treatment and did not diminish over the 12 weeks of treatment (Figure 1). Other spirometry measures (peak $\mathrm{FEV}_{1}$, trough $\mathrm{FEV}_{1}, \mathrm{FEV}_{1}$ at each timepoint, $\mathrm{FVC} \mathrm{AUC}_{0-12}$ ) were also significantly improved with FFIS treatment compared with placebo at each visit. Results for the FA treatment group were similar to those for FFIS for each primary and secondary efficacy endpoint.

The improvement in bronchodilation was similar to that observed in previous studies of maintenance treatment with formoterol DPI ${ }^{15-17}$ and others, summarized by Steiropoulos et al, ${ }^{3}$ and the improvement of $185 \mathrm{~mL}^{14}$ would be considered clinically relevant to the patient. ${ }^{18}$ No decline in bronchodilation effectiveness was observed over the 12-week treatment period with FFIS. This result is in contrast to those reported for the other nebulized LABA product, arformoterol, and for salmeterol, in which some tolerance developed within 12 weeks at all doses tested, ${ }^{19,20}$ although meaningful pulmonary function improvements were maintained throughout a one-year study of arformoterol. ${ }^{21}$

Health-related quality of life improvements as demonstrated by total scores on the St George's Respiratory Questionnaire (SGRQ) as well as symptoms and impacts scores were observed with FFIS treatment (Figure 2), whereas FA-treated participants only demonstrated improvement in symptoms scores. ${ }^{14}$ These mean improvements in FFIS-treated participants were $\geq 4$ units, the threshold for clinically significant changes. ${ }^{22}$ Treatment with FFIS or FA also led to a $42 \%$ reduction in rescue albuterol use beginning in the first assessment period (day 1-week 4) and lasting throughout the 12 weeks of treatment.

The effect of twice-daily FFIS nebulizer treatment on pulmonary function was also compared to that of the marketed four-times-daily metered dose inhaler combination ipratropium/albuterol product (Combivent ${ }^{\circledR}$, IPR-ALB) in an open-label crossover study. The primary efficacy outcome (mean morning pre-dose $\mathrm{FEV}_{1}$ or trough) was significantly higher in the FFIS group after 2 weeks of treatment. ${ }^{7}$ Using a newly developed questionnaire, participants reported greater satisfaction with treatment, 


\section{Day 1}

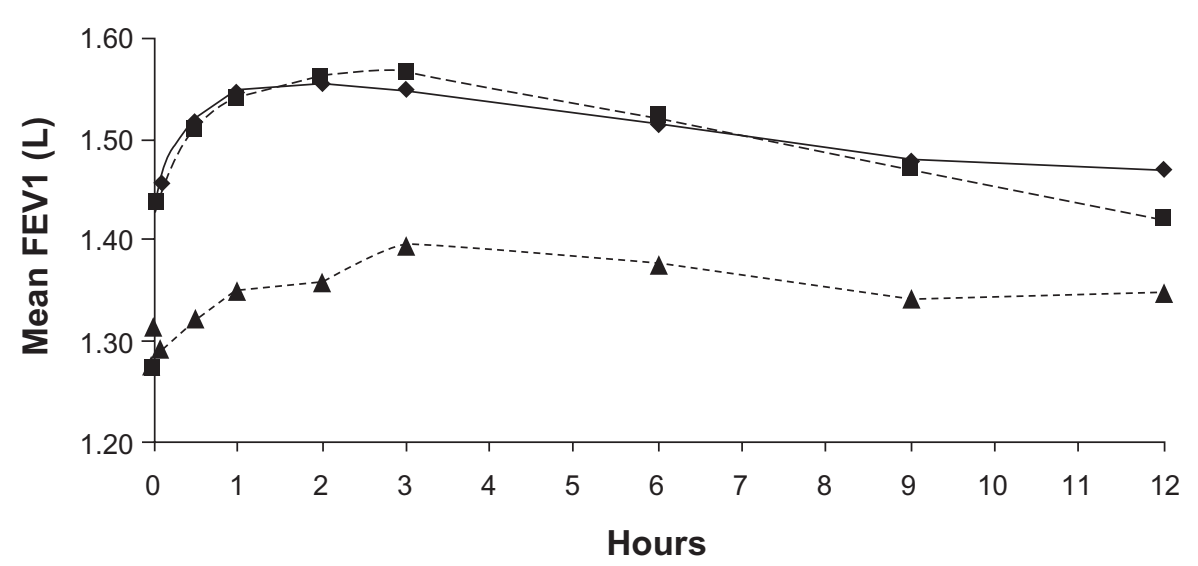

Week 12

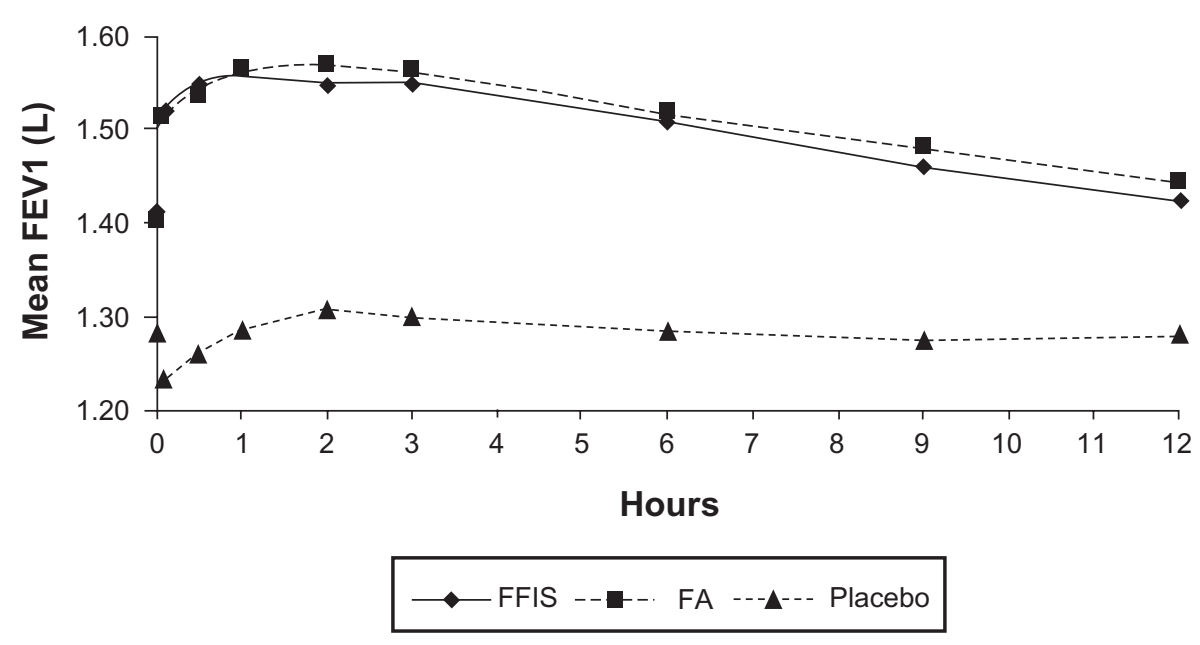

Figure I Time course of mean FEV, response after first dose (Day I) and I2 weeks of treatment in the ITT population.

Notes: FFIS: formoterol fumarate inhalation solution $20 \mu \mathrm{g}$ BID and FA: formoterol fumarate DPI I $2 \mu \mathrm{g}$ BID. Data expressed as LS means adjusted for baseline FEV . LS mean difference at each timepoint on Day I and Week I2: $P \leq 0.0007$ and FA versus placebo $P<0.05$.

Reprinted from Respiratory Medicine Volume 102, Gross NJ, Nelson HS, Lapidus RJ, et al. Efficacy and safety of formoterol fumarate delivered by nebulization to COPD patients, pp. 189-197. Copyright (C 2008, with permission from Elsevier.

a greater perception that the medication reached the lungs, and more control of their COPD when using FFIS compared with IPR-ALB. Subgroup analyses by age, gender, and severity demonstrated that FFIS was significantly more effective than IPR-ALB and resulted in greater satisfaction in participants who were older, male, or had more severe COPD. Patients with more severe disease also preferred FFIS to IPR-ALB treatment.

\section{Safety}

Results of recent meta-analyses and reviews have raised concerns regarding cardiovascular and other adverse effects of LABA treatment of COPD and asthma. ${ }^{23,24}$ In the pivotal safety and efficacy study, the incidence of adverse events (AEs) was similar across treatment groups $(51 \%-60 \%)$, with the number of respiratory events, including COPD exacerbations, trending higher in the placebo group. ${ }^{14}$ The most frequently reported AEs were headache (FFIS: 5.7\%, FA: 4.4\%, PLA: $7.0 \%$ ), nausea (FFIS: $4.9 \%$, FA: 3.5\%, PLA: $2.6 \%$ ), diarrhea (FFIS: $4.9 \%$, FA: $1.8 \%$, PLA: $3.5 \%$ ), COPD exacerbation (FFIS: $4.1 \%$, FA: $6.1 \%$, PLA: 7.9\%), dizziness (FFIS: 2.4\%, FA: $7.0 \%$, PLA: 0.9\%), and cough (FFIS: $1.6 \%$, FA: $4.4 \%$, PLA: $4.4 \%$ ). There were no deaths or drug-related serious AEs, and the discontinuations from AEs occurred in $3.3 \%, 3.5 \%$, and $8.8 \%$ of participants in the FFIS, FA, and placebo groups, respectively. Three participants (one in each group) discontinued after AEs of possible cardiac significance..$^{25}$ 


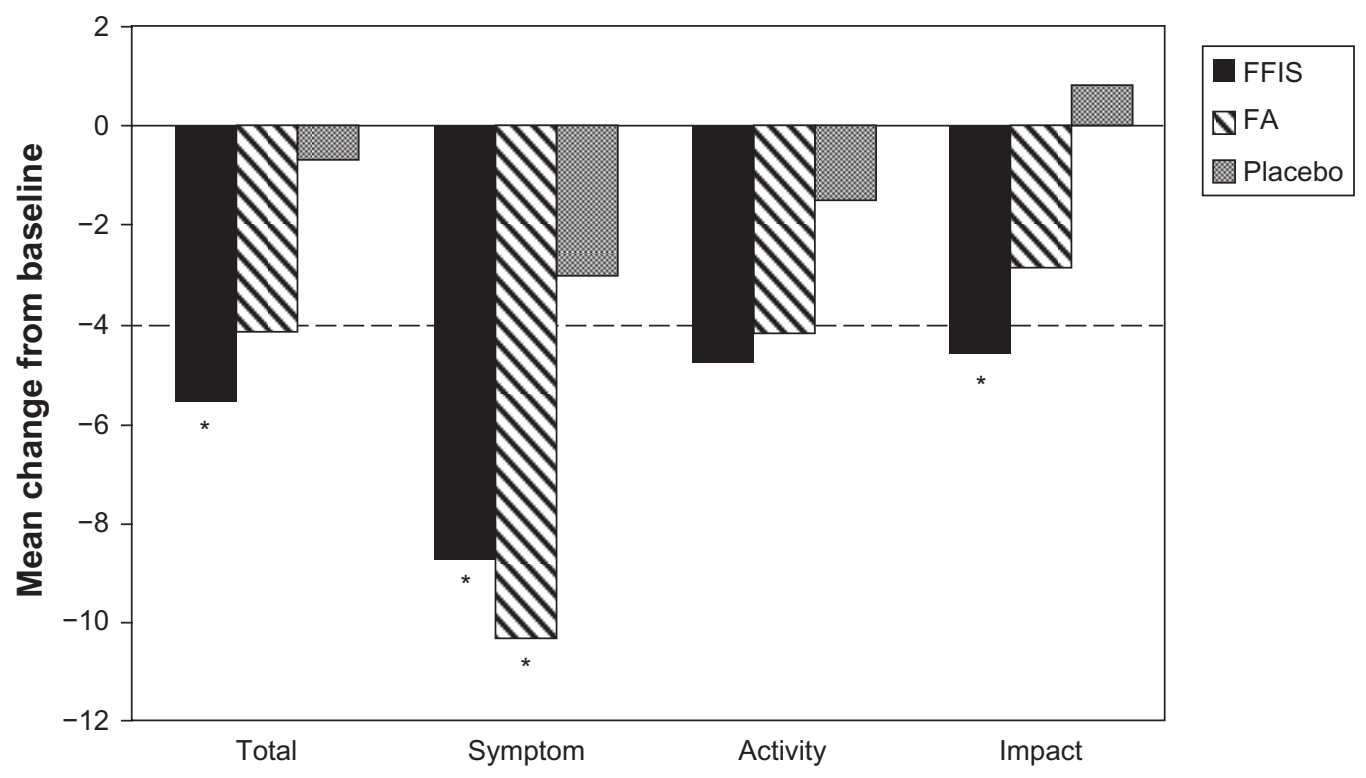

Figure 2 Change from baseline in SGRQ scores (LS means) after 12 weeks of treatment (or early termination). FFIS: formoterol fumarate inhalation solution $20 \mu g$ BID and FA: formoterol fumarate DPI $12 \mu \mathrm{g}$ BID. " $P \leq 0.03$ versus placebo, (---): clinically meaningful change.

Reprinted from Respiratory Medicine Volume 102, Gross NJ, Nelson HS, Lapidus RJ, et al. Efficacy and safety of formoterol fumarate delivered by nebulization to COPD patients, pp. 189-197, Copyright (C) 2008, with permission from Elsevier.

Long-term safety was assessed in 569 participants in a 52-week active-control, open-label safety study. ${ }^{26}$ Most participants treated with FFIS (86\%) completed at least 6 months of treatment compared with $88 \%$ treated with FA. Comparable numbers of FFIS and FA participants experienced at least one AE (Table 2), most of which were mild or moderate. Similar rates of death (1.3\% FFIS, 1.9\% FA), discontinuation due to AEs (39\% FFIS, 36\% FA), and serious AEs (16\% FFIS, 18\% FA) were observed.

In the long-term study, laboratory evaluations demonstrated little change in mean values from baseline to Week 10 or Week 52 for any parameter. More than 5\% of participants

Table 2 Treatment emergent adverse events (TEAE) reported in $\geq 3 \%$ of participants in either group

\begin{tabular}{|c|c|c|}
\hline & $\begin{array}{l}\text { Formoterol fumarate } \\
\text { inhalation solution } 20 \mu \mathrm{g} \text { BID } \\
(\mathrm{n}=463)\end{array}$ & $\begin{array}{l}\text { Formoterol fumarate dry } \\
\text { powder inhalation I } 2 \mu \mathrm{g} \text { BID } \\
(\mathrm{n}=106)\end{array}$ \\
\hline Number (\%) with $\geq$ I TEAE & $340(73.4)$ & $83(78.3)$ \\
\hline COPD exacerbation & $73(15.8)$ & $19(17.9)$ \\
\hline Upper respiratory tract infection & $47(10.2)$ & $13(12.3)$ \\
\hline Nasopharyngitis & $36(7.8)$ & $7(6.6)$ \\
\hline Bronchitis & $32(6.9)$ & $10(9.4)$ \\
\hline Sinusitis & $27(5.8)$ & $4(3.8)$ \\
\hline Acute bronchitis & $22(4.8)$ & $3(2.8)$ \\
\hline Urinary tract infection & $21(4.5)$ & $6(5.7)$ \\
\hline Headache & $20(4.3)$ & $5(4.7)$ \\
\hline Cough & $19(4.1)$ & $4(3.8)$ \\
\hline Pneumonia & $18(3.9)$ & $2(1.9)$ \\
\hline Arthralgia & $15(3.2)$ & $5(4.7)$ \\
\hline Diarrhea & $16(3.5)$ & $2(1.9)$ \\
\hline Hypertension & $14(3.0)$ & $3(2.8)$ \\
\hline Back pain & $13(2.8)$ & $7(6.6)$ \\
\hline Insomnia & II (2.4) & $5(4.7)$ \\
\hline Dyspnea & $7(1.5)$ & $5(4.7)$ \\
\hline Dizziness & $6(1.3)$ & $4(3.8)$ \\
\hline Tooth abscess & $\mathrm{I}(0.2)$ & $4(3.8)$ \\
\hline
\end{tabular}

From Donohue JF, Hanania NA, Fogarty C, et al. Long-term safety of nebulized formoterol: results of a twelve-month open-label clinical trial. Ther Adv Resp Dis 2008;2: 199-208. Copyright (c) 2008 by Sage Publications.

Reprinted with permission from Sage. 
experienced changes from normal to high in serum creatinine, uric acid, glucose, sodium, white blood cell count, and neutrophils, a result similar between treatment groups. In the FFIS group, mean changes from baseline to Week 52 for serum glucose and potassium were $0.4 \mathrm{mg} / \mathrm{dL}$ and $0.0 \mathrm{mEq} / \mathrm{L}$, respectively. The incidence of clinically significant changes in laboratory values was low in each group.

Cardiac effects of FFIS treatment were monitored carefully in the 12-week pivotal study. ${ }^{25}$ Although patients were excluded from the trial if they had an unstable cardiac condition, recent myocardial infarction, or QTc interval $>0.46 \mathrm{~ms}$, approximately $50 \%$ of enrolled patients demonstrated cardiac abnormalities on screening ECGs, which was similar across treatment groups. The underlying comorbidities associated with COPD, including increased incidence of cardiovascular disease, ${ }^{27-29}$ are confounding factors in any analysis of COPD treatment. As many as half of COPD patients may have undiagnosed atrial tachycardia ${ }^{29}$ and one-fifth may have heart failure. ${ }^{28}$ Neither FFIS nor FA treatment had clinically meaningful effects on mean or maximum heart rate (HR) or incidence of ventricular premature beats found with 24-hour Holter monitoring. ${ }^{25}$ The incidence of arrhythmic events was also similar across groups and did not increase significantly throughout the study. ECG measurements demonstrated that mean changes from baseline in HR, PR interval, QRS complex, QT interval, and R-R interval were comparable among the treatment groups at each time point. The proportions of participants who had a mean maximum change in QTc $\geq 60 \mathrm{~ms}$ at any

Table 3 Maximum change from baseline in $\mathrm{QTcB}$ and QTcF during 12 weeks' treatment with formoterol fumarate inhalation solution $20 \mu \mathrm{g}$ BID (FFIS group), formoterol fumarate dry powder inhaler $12 \mu \mathrm{g}$ BID (FA group), or placebo in patients with chronic obstructive pulmonary disease

\begin{tabular}{|c|c|c|c|}
\hline \multirow[t]{2}{*}{ Category } & FFIS & FA & Placebo \\
\hline & $(n=122)$ & $(n=112)$ & $(n=I I I)$ \\
\hline \multicolumn{4}{|l|}{$\overline{Q T c B}$} \\
\hline$<30 \mathrm{~ms}$ & $100(82.0)$ & 91 (8I.3) & $93(83.8)$ \\
\hline $30-<60 \mathrm{~ms}$ & $22(18.0)$ & $19(17.0)$ & $16(14.4)$ \\
\hline$\geq 60 \mathrm{~ms}$ & 0 & $2(1.8)$ & $2(1.8)$ \\
\hline \multicolumn{4}{|l|}{$\mathrm{QTcF}$} \\
\hline$<30 \mathrm{~ms}$ & $109(89.3)$ & $95(84.8)$ & 99 (89.2) \\
\hline $30-<60 \mathrm{~ms}$ & II (9.0) & $16(14.3)$ & II (9.9) \\
\hline$\geq 60 \mathrm{~ms}$ & $2(1.6)$ & I (0.9) & I (0.9) \\
\hline
\end{tabular}

Notes: Values are no. (\%) of patients. QTcB $=\mathrm{QT}$ interval corrected for heart rate (Bazett's correction), QTcF $=$ QT interval corrected for heart rate (Fridericia's correction).

Reprinted with permission of the publisher from: Nelson HS, Gross NJ, Levine B, et al. Cardiac safety profile of nebulized formoterol in adults with COPD. Clinical Therapeutics. 2007;29:2167-2178. Copyright () 2007 by Excerpta Medica, Inc. time during the study were also comparable among groups (Table 3). Cardiovascular safety was also monitored in the 52-week study with ECGs at baseline, Week 10, and Week 52 (or early termination). Effects were small and comparable between treatment groups.

The results of the FFIS studies confirmed those of other large studies using an equivalent dose of formoterol DPI $(12 \mu \mathrm{g})^{17,30-32}$ and demonstrated no adverse cardiovascular effects of nebulized formoterol treatment for 12 or 52 weeks in COPD participants. Unlike the previous meta-analysis, ${ }^{23}$ there was no correlation between a decrease in potassium levels and duration of formoterol treatment in these studies. Glucose levels, which rise in a dose-dependent manner with $\beta_{2}$-agonist treatment, ${ }^{12}$ were unaffected by formoterol treatment. There were also no increases in mortality, serious adverse events, or COPD exacerbations with FFIS treatment in these studies. A recent large case-controlled study ${ }^{33}$ and a systematic review ${ }^{34}$ demonstrated the lack of increased risks of COPD exacerbations, cardiovascular deaths, respiratory deaths, or all-cause mortality with LABA treatment for COPD and, in fact, demonstrated the reduced risk of all-cause mortality ${ }^{33}$ and COPD exacerbations. ${ }^{34}$ A post-marketing surveillance study of formoterol DPI prescribed for 5,777 patients with respiratory disease in the United Kingdom, 65\% of whom had $>12$ months treatment, also demonstrated the tolerability of formoterol. ${ }^{32}$

\section{Add-on studies with tiotropium}

The efficacy and safety of adding twice-daily nebulized formoterol treatment to once-daily maintenance treatment with tiotropium (Spiriva $^{\circledR}$, TIO) were evaluated in moderate-tosevere COPD participants randomized to receive FFIS $20 \mu \mathrm{g}$ or nebulized placebo while maintaining treatment with TIO for 6 weeks in two studies. Bronchodilation, as defined by the primary efficacy endpoint $\mathrm{FEV}_{1} \mathrm{AUC}_{0-3}$ at week 6, was significantly improved with the addition of FFIS to maintenance TIO by $185-190 \mathrm{~mL}$ over placebo. ${ }^{35-37} \mathrm{FEV}_{1}$ measured pre- and post-dose over 3 hours on day 1 and week 6 is shown in Figure 3, illustrating the significant improvements in $\mathrm{FEV}_{1}$ after treatment with FFIS at the beginning and end of the study period. A gain of $410 \mathrm{~mL}$ with FFIS added to TIO compared with $280 \mathrm{~mL}$ with the addition of placebo to TIO was observed in the second study. ${ }^{36}$ Pre-dose inspiratory capacity (IC) did not significantly differ between treatment groups in either study; however, post-dose IC, measured only in the second study, ${ }^{36}$ was significantly improved by FFIS/ TIO treatment versus PLA/TIO both on day 1 and week 6 (Figure 4). 


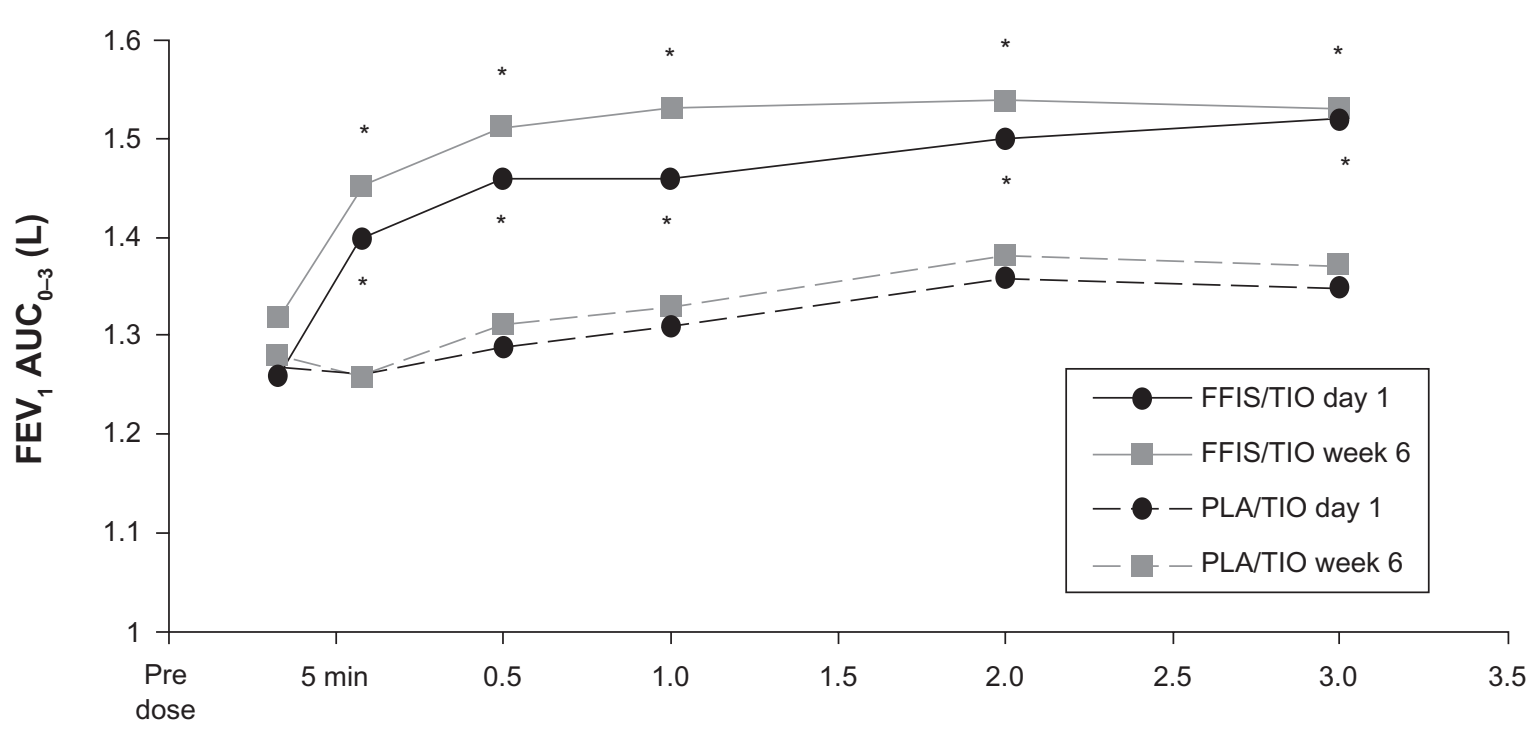

Hours post-dose

Figure 3 Time course of mean FEV, response after first dose (Day I) and 6 weeks of treatment in the ITT population.

Notes: $\mathrm{FFIS/TIO} \mathrm{=} \mathrm{formoterol} \mathrm{fumarate} \mathrm{inhalation} \mathrm{solution} 20 \mu \mathrm{g}$ BID and tiotropium bromide inhalation powder $18 \mu \mathrm{g}$ QD, PLA/TIO = placebo inhalation solution BID and tiotropium bromide inhalation powder $18 \mu \mathrm{g}$ QD. Data expressed as LS means adjusted for baseline FEV $.{ }^{*} P \leq 0.0003$ versus PLA/TIO.

Reprinted from Respiratory Medicine Volume 102, Tashkin DP, Littner M, Andrews CP, et al. Concomitant treatment with nebulized formoterol and tiotropium in subjects with COPD: a placebo-controlled trial, pp. 479-487. Copyright @) 2008, with permission from Elsevier.

Baseline dyspnea was similar between groups in both studies. After 6 weeks of treatment, however, there was a difference in TDI scores between groups favoring FFIS/TIO, with a mean difference from placebo of 1.80 in the first study $(P=0.0002)^{35}$ and 0.72 in the second study $(P=0.11) .{ }^{36}$ More participants receiving FFIS/TIO experienced a clinically meaningful improvement $(\geq 1)^{38}$ in dyspnea $(57.7 \%$ versus $31.1 \%$ with PLA/TIO, Figure 5$) ;{ }^{35}$ similar responder rates were observed in the second study $(58.4 \%$ versus $47.2 \%$ with PLA/TIO). ${ }^{36}$ Several respiratory symptoms (total, shortness

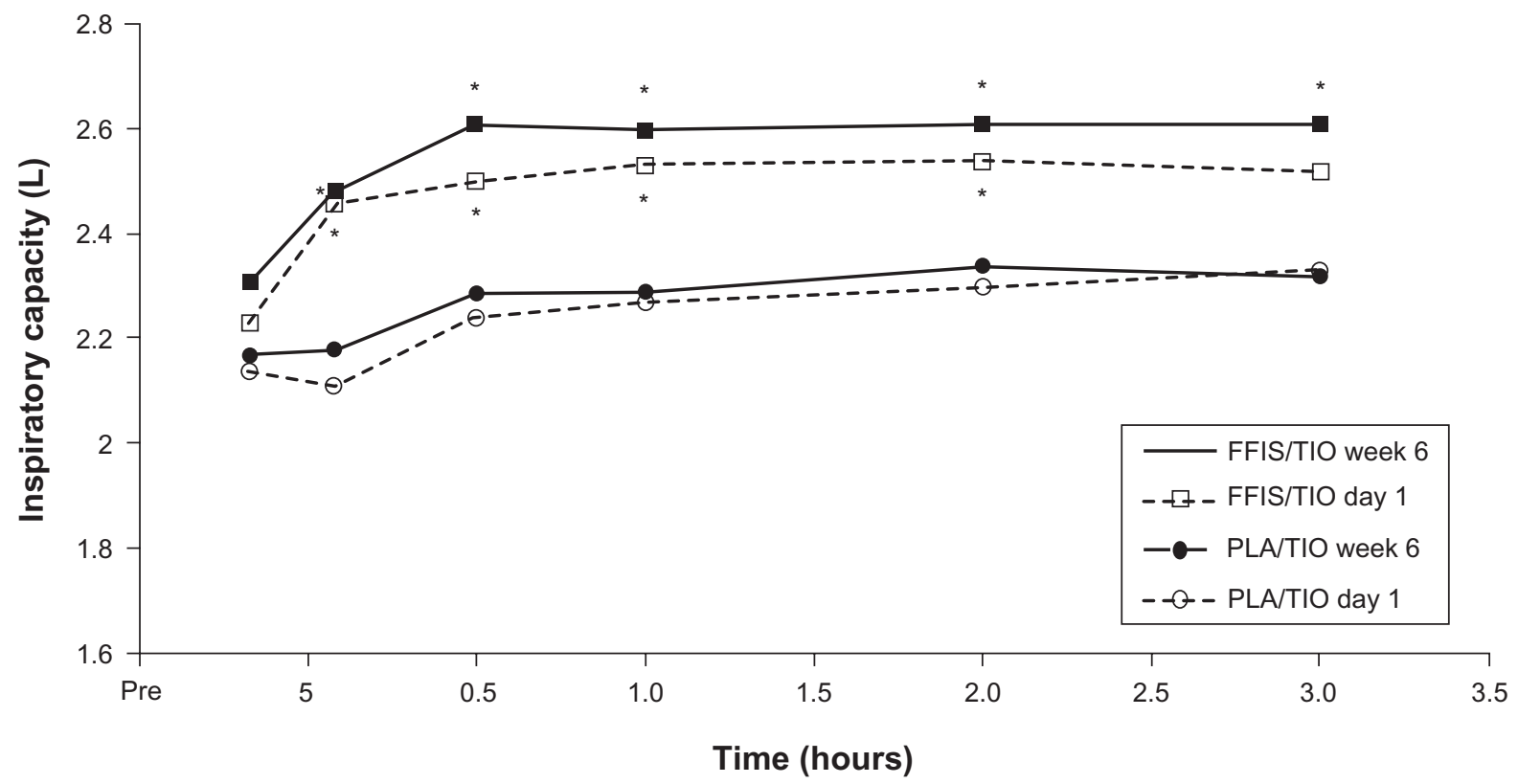

Figure 4 Time course of mean inspiratory capacity before and after first dose (Day I) and 6 weeks of treatment in the ITT population.

Notes: $\mathrm{FFIS/TIO} \mathrm{=} \mathrm{formoterol} \mathrm{fumarate} \mathrm{inhalation} \mathrm{solution} 20 \mu \mathrm{g}$ BID plus tiotropium bromide inhalation powder I8 $\mu \mathrm{g}$ QD, PLA/TIO = placebo inhalation solution BID plus tiotropium bromide inhalation powder $18 \mu \mathrm{g}$ QD. ${ }^{*} \mathrm{P} \leq 0.005$ versus PLA/TIO.

Reproduced from Hanania NA, Boota A, Kerwin E, et al. Efficacy and safety of nebulized formoterol as add-on therapy in COPD patients receiving maintenance tiotropium bromide, Drugs 2009;69:1205-1216 with permission from Adis, a Wolters Kluwer business (C Adis Data Information BF [2009]. All rights reserved.) 


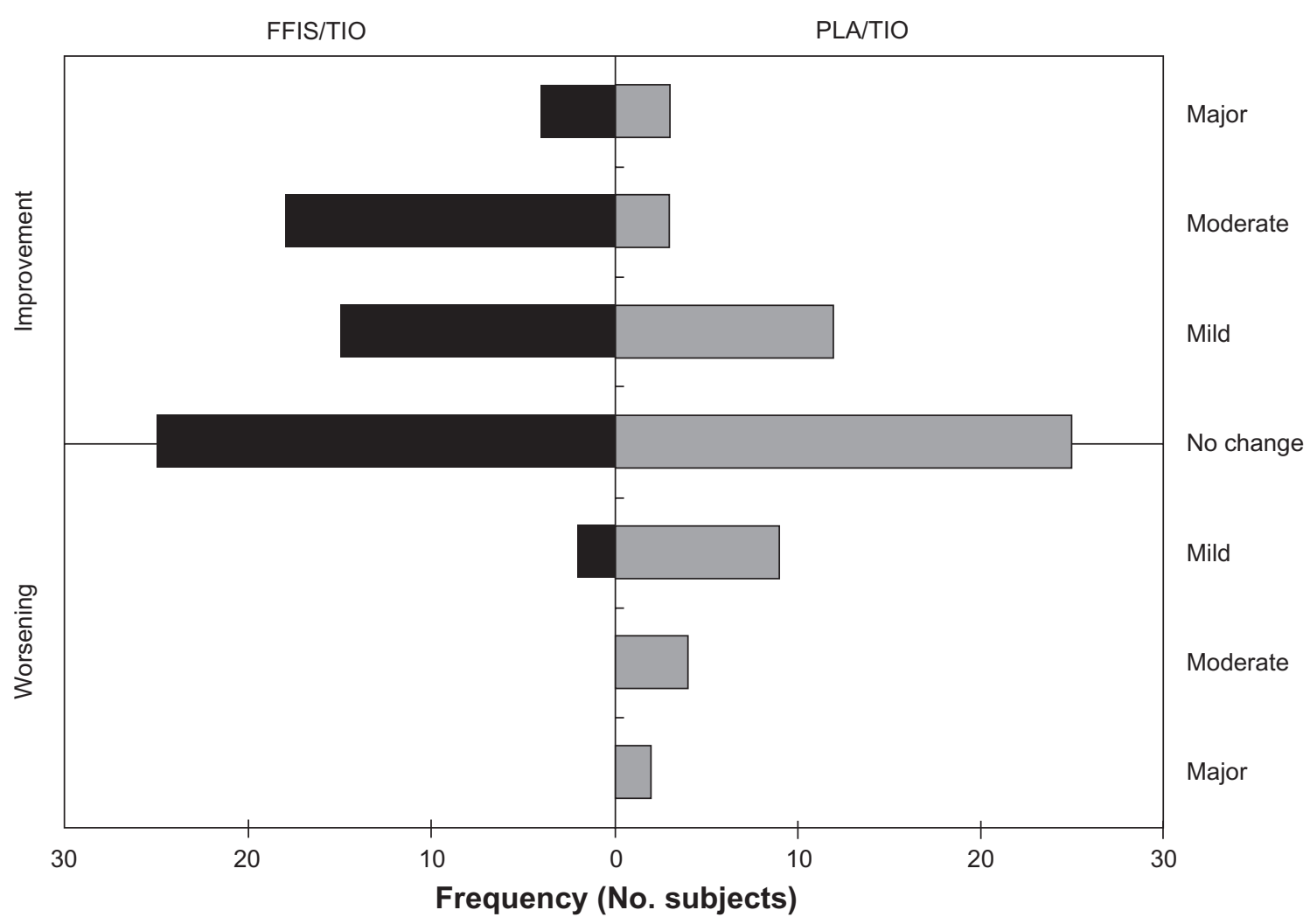

Figure 5 Frequency distribution of TDI scores.

Notes: FFIS/TIO = formoterol fumarate inhalation solution $20 \mu \mathrm{g}$ BID and tiotropium bromide inhalation powder I8 $\mu \mathrm{g}$ QD, PLA/TIO = placebo inhalation solution BID and tiotropium bromide inhalation powder $18 \mu \mathrm{g}$ QD. Mild, moderate, and major improvement indicates TDI scores of + I to $+3,+4$ to +6 , and +7 to +9 , respectively; mild, moderate, and major worsening indicates TDI scores of $-I$ to $-3,-4$ to -6 , and -7 to -9 , respectively.

Reprinted from Respiratory Medicine Volume 102, Tashkin DP, Littner M, Andrews CP, et al. Concomitant treatment with nebulized formoterol and tiotropium in subjects with COPD: a placebo-controlled trial, pp. 479-487. ${ }^{35}$ Copyright (C) 2008, with permission from Elsevier.

of breath, chest tightness, nighttime awakenings) were significantly improved with FFIS/TIO use compared with PLA/ TIO in one study, ${ }^{35}$ but only shortness of breath demonstrated a difference at two timepoints during the other study. ${ }^{36}$ Rescue albuterol use was significantly reduced with FFIS/TIO over PLA/TIO treatment in both studies.

Health-related quality of life (SGRQ) scores did not differ between groups after TIO run-in or after the treatment period in either study, with the exception of an improved change in symptoms score in the FFIS/TIO group in one study. ${ }^{35}$ Also, the number of participants experiencing a clinically meaningful improvement in SGRQ $(>4)^{22}$ was greater in the FFIS/TIO group in the total score and individual components in both studies.

These results are not surprising, as they have also been reported previously with maintenance treatment with formoterol DPI plus tiotropium ${ }^{39-43}$ and were recently well summarized. ${ }^{44}$ However, the degree of the benefit in lung function by using two bronchodilators with distinct mechanisms of action was dramatic and occurred after a lengthy run-in period with tiotropium designed to stabilize its effect on pulmonary function. The rapid onset of bronchodilation with formoterol administration compared with tiotropium may contribute to its additive benefit. ${ }^{45}$ Treatment with both formoterol and tiotropium has been demonstrated to provide greater improvement in lung function than the LABA/ICS combination of salmeterol and fluticasone. ${ }^{46}$ The improvement in post-dose inspiratory capacity and dyspnea may be linked due to the beneficial effects of LABAs on small airway patency, improving the hallmark pulmonary hyperinflation of COPD. ${ }^{47}$ The observed benefits in these nebulized formoterol studies support recent recommendations to combine therapies when needed to treat COPD. ${ }^{1,48}$

Adverse events are summarized with greater power by combining results from the two almost identical trials with FFIS/TIO.$^{37}$ More participants treated with PLA/TIO experienced adverse events (45.7\% compared with 31.0\% for FFIS/TIO), including a greater number of COPD exacerbations. More PLA/TIO participants withdrew due to AEs and had serious AEs (cellulitis, pneumonia, COPD exacerbation, angina) than those treated with FFIS/TIO. Clinical laboratory evaluations were generally within normal range 
at screening and week 6. One participant treated with FFIS/ TIO experienced a clinically significant decrease in serum potassium to $3.1 \mathrm{mmol} / \mathrm{L}$. ECG changes were minimal throughout the studies, with change in mean heart rate being greater for PLA/TIO in one study $(1.5 \mathrm{bpm}$ versus $0.2 \mathrm{bpm}$ for FFIS/TIO) ${ }^{35}$ and for FFIS/TIO in the other (1.3 bpm versus $0.8 \mathrm{bpm}$ for PLA/TIO). ${ }^{36}$ Changes in QTcB $\geq 60 \mathrm{~ms}$ were observed in 3 FFIS/TIO and 3 PLA/TIO participants in the two studies.

Previous large placebo-controlled trials demonstrated that tiotropium added to baseline COPD medications including inhaled corticosteroids and LABAs reduced COPD exacerbations. ${ }^{49,50}$ These FFIS + TIO study results suggest that there may be a safety benefit of adding nebulized formoterol to tiotropium, supporting a recent 6-month study of formoterol DPI plus tiotropium that found a reduction in COPD exacerbations compared with tiotropium alone..$^{40}$ The results of these studies do not support previous suggestions that LABA treatment for COPD may result in adverse safety consequences, including adverse cardiovascular effects, increased mortality, and increased respiratory mortality, ${ }^{23,24}$ although a treatment arm using nebulized formoterol alone was not included, making it more difficult to assess the safety benefit in these studies. Clearly, further studies, including long-term studies using the combination of drugs, will be required to explore the possible safety benefit for COPD patients of adding nebulized formoterol treatment to maintenance tiotropium.

\section{Summary}

In conclusion, a nebulized formulation of formoterol (Perforomist $^{\circledR}$ ) $20 \mu \mathrm{g} / 2 \mathrm{~mL}$ results in lung function changes that closely resemble those of the approved formoterol dry powder formulation (Foradil ${ }^{\circledR}$ ) $12 \mu \mathrm{g}$, specifically the rapid onset of action and significant bronchodilation throughout the subsequent 12 hours, without any loss of efficacy, subsensitivity, or tachyphylaxis, during 12 weeks of regular twice daily administration. The safety and adverse event profiles were not different from that of placebo or Foradil ${ }^{\circledR}$ dry powder. Cardiac outcomes in particular revealed no concern of increased rhythm disturbances. The nebulized formulation was well accepted by patients with COPD, being preferred to the dry powder agent by many. Even in COPD patients who had been stabilized on maintenance once daily tiotropium, the addition of nebulized formoterol resulted in significant further improvement in lung function. Perforomist ${ }^{\circledR}$ is safe and effective for maintenance treatment of COPD in patients who require a nebulized formulation of a long-acting betaagonist.

\section{Acknowledgments/Disclosure}

The authors wish to acknowledge the editorial assistance of Elizabeth (Betts) Field, PhD, of Field Advantage Medical Communications, which was funded by Dey Pharma, L.P., the manufacturers of Perforomist ${ }^{\circledR}$.

\section{References}

1. Global Initiative for Chronic Obstructive Lung Disease (GOLD). Global strategy for the diagnosis, management, and prevention of chronic obstructive pulmonary disease. 2008 Update. National Institutes of Health/WHO. Available at: http://www.goldcopd.org Accessed Jan 5, 2009.

2. Benhamou D, Cuvelier A, Muir JF, et al. Rapid onset of bronchodilation in COPD: a placebo-controlled study comparing formoterol (Foradil ${ }^{\circledR}$ Aerolizer $^{\mathrm{TM}}$ ) with salbutamol (Ventodisk ${ }^{\mathrm{TM}}$ ). Respir Med. 2001;95: $817-821$.

3. Steiropoulos P, Tzouvelekis A, Bouros D. Formoterol in the management of chronic obstructive pulmonary disease. Int J Chron Obstruct Pulmon Dis. 2008;3:205-215.

4. Tashkin DP, Klein GL, Colman SS, Zayed H, Schonfeld WH. Comparing COPD treatment: nebulizer, metered dose inhaler, and concomitant therapy. Am J Med. 2007;120:435-441.

5. Dolovich MB, Ahrens RC, Hess DR, et al. Device selection and outcomes of aerosol therapy: evidence-based guidelines: American College of Chest Physicians/American College of Asthma, Allergy, and Immunology. Chest. 2005;127:335-371.

6. Gross NJ, Kerwin E, Levine B, et al. Nebulized formoterol fumarate: dose selection and pharmacokinetics. Pulm Pharmacol Ther. 2008; 21:818-823.

7. Sutherland ER, Brazinsky S, Feldman G, McGinty J, Tomlinson L, Denis-Mize K. Nebulized formoterol effect on bronchodilation and satisfaction in COPD patients compared to QID ipratropium/albuterol MDI. Curr Med Res Opin. 2009;25:653-661.

8. Lecaillon JB, Kaiser G, Palmisano M, Morgan J, Della Cioppa G. Pharmacokinetics and tolerability of formoterol in healthy volunteers after a single high dose of Foradil dry powder inhalation via aerolizer ${ }^{\mathrm{TM}}$. Eur J Clin Pharmacol. 1999;55:131-138.

9. Kottakis J, Della Cioppa G, Creemers J, et al. Faster onset of bronchodilation with formoterol than with salmeterol in patients with stable, moderate to severe COPD: results of a randomized, double-blind clinical study. Can Respir J. 2002;9:107-115.

10. Ringdal N, Derom E, Wahlin-Boll E, Pauwels R. Onset and duration of action of single doses of formoterol inhaled via Turbulhaler ${ }^{\circledR}$. Respir Med. 1998;92:1017-1021.

11. Derom E. Lung deposition and efficacy of inhaled formoterol in patients with moderate to severe COPD. Respir Med. 2007;1001: 1931-1941.

12. Guhan AR, Cooper S, Oborne J, Lewis S, Bennett J, Tatters field AE. Systemic effects of formoterol and salmeterol: a doseresponse comparison in healthy subjects. Thorax. 2000;55: $650-656$.

13. Foradil [package insert]. East Hanover, NJ. Novartis Pharmaceuticals Corp.

14. Gross NJ, Nelson HS, Lapidus RJ, et al. Efficacy and safety of formoterol fumarate delivered by nebulization to COPD patients. Respir Med. 2008;102:189-197.

15. Dahl R, Greefhorst LAPM, Nowak D, et al. Inhaled formoterol dry powder versus ipratropium bromide in chronic obstructive pulmonary disease. Am J Respir Crit Care Med. 2001;164: 778-784.

16. Aalbers R, Ayres J, Backer V, et al. Formoterol in patients with chronic obstructive pulmonary disease: a randomized, controlled, 3-month trial. Eur Respir J. 2002;19:936-943. 
17. Rossi A, Kristufek P, Levine BE, et al. Comparison of the efficacy, tolerability, and safety of formoterol dry powder and oral, slowrelease theophylline in the treatment of COPD. Chest. 2002;121: 1058-1069.

18. Donohue JF. Minimal clinically important differences in COPD lung function. COPD. 2005;2:111-124.

19. Baumgartner RA, Hanania NA, Calhoun WJ, Sahn SA, Sciarappa K, Hanrahan JP. Nebulized arformoterol in patients with COPD: a 12-week, multicenter, randomized, double-blind, double-dummy, placebo- and active-controlled trial. Clin Ther. 2007;29:261-278.

20. Hanrahan JP, Hanania NA, Calhoun WJ, et al. Effect of nebulized arformoterol on airway function in COPD: results from two randomized trials. COPD. 2008;5:25-34.

21. Donohue JF, Hanania NA, Sciarappa KA, et al. Arformoterol and salmeterol in the treatment of chronic obstructive pulmonary disease: a one year evaluation of safety and tolerance. Ther Adv Resp Dis. 2008; $2: 37-48$

22. Jones PW. Interpreting thresholds for a clinically significant change in health status in asthma and COPD. Eur Respir J. 2002;19:398-404.

23. Salpeter SR, Ormiston TM, Salpeter EE. Cardiovascular effects of $\beta$-agonists in patients with asthma and COPD: a meta-analysis. Chest. 2004;125:2309-2321.

24. Salpeter SR. Cardiovascular safety of $\beta_{2}$-adrenoceptor agonist use in patients with obstructive airway disease. Drugs Aging. 2004;21: 405-414.

25. Nelson HS, Gross NJ, Levine B, Kerwin EM, Rinehart M, DenisMize K; for the Formoterol Study Group. Cardiac safety profile of nebulized formoterol in adults with COPD: a 12-week, multicenter, randomized, double-blind, double-dummy, placebo- and active-controlled trial. Clin Ther. 2007;29:2167-2178.

26. Donohue JF, Hanania NA, Fogarty C, Campbell SC, Rinehart M, Denis-Mize K. Long-term safety of nebulized formoterol: results of a twelve-month open-label clinical trial. Ther Adv Resp Dis. 2008; 2: 199-208.

27. Sin DD, Anthonisen NR, Soriano JB, Agusti AG. Mortality in COPD: role of comorbidities. Eur Respir J. 2006;28:1245-1257.

28. Rutten FH, Cramer M-JM, Grobbee DE, et al. Unrecognized heart failure in elderly patients with stable chronic obstructive pulmonary disease. Eur Heart J. 2005;26:1887-1894.

29. Finkelstein J, Cha E, Scharf SM. Chronic obstructive pulmonary disease as an independent risk factor for cardiovascular morbidity. Int J Chron Obstruct Pulmon Dis. 2009;4:337-349.

30. Campbell SC, Criner GJ, Levine BE, et al. Cardiac safety of formoterol $12 \mu \mathrm{g}$ twice daily in patients with chronic obstructive pulmonary disease. Pulm Pharmacol Ther. 2007;20:571-579.

31. Ogale SS, Lee TA, Sullivan SD. The risk of cardiovascular events associated with inhaled long-acting beta-2-adrenoreceptor agonists in patients with chronic obstructive pulmonary disease. Chest. 2006; 130 Suppl:121S-122S[abstract].

32. Wilton LV, Shakir SA. A post-marketing surveillance study of formoterol (Foradil): its use in general practice in England. Drug Saf. 2002;25:213-223

33. Lee TA, Pickard AS, Au DH, Bartle B, Weiss KB. Risk for death associated with medications for recently diagnosed chronic obstructive pulmonary disease. Ann Int Med. 2008;149:380-390.
34. Rodrigo GJ, Nannini LJ, Rodriguez-Roisin R. Safety of long-acting $\beta$-agonists in stable COPD: a systematic review. Chest. 2008;133: 1079-1087.

35. Tashkin DP, Littner M, Andrews CP, Tomlinson L, Rinehart M, Denis-Mize K. Concomitant treatment with nebulized formoterol and tiotropium in subjects with COPD: a placebo-controlled trial. Respir Med. 2008;102:479-487.

36. Hanania NA, Boota A, Kerwin E, Tomlinson L, Denis-Mize K. Efficacy and safety of nebulized formoterol as add-on therapy in COPD patients receiving maintenance tiotropium bromide. Drugs. 2009;69: 1205-1216

37. Tashkin DP, Hanania NA, McGinty J, Denis-Mize K, Chaudry I. Nebulized formoterol provides added benefits to tiotropium treatment in COPD. Adv Ther. 2009;26:1024-1034.

38. Witek TJ Jr, Mahler DA. Minimal important difference of the transition dyspnoea index in a multinational clinical trial. Eur Respir J. 2003; 21:267-272

39. Tashkin D, Pearle J, Iezzoni D, Varghese ST. Formoterol and tiotropium compared with tiotropium alone for treatment of COPD. COPD. 2009;6:17-25.

40. Vogelmeier C, Kardos P, Harari S, Gans SJ, Stenglein S, Thirlwell J. Formoterol mono- and combination therapy with tiotropium in patients with COPD: a 6-month study. Respir Med. 2008;102:1511-1520.

41. van Noord JA, Aumann JL, Janssens E, et al. Comparison of tiotropium once daily, formoterol twice daily and both combined once daily in patients with COPD. Eur Respir J. 2005;26:214-222.

42. van Noord JA, Aumann JL, Janssens E, et al. Effects of tiotropium with and without formoterol on airflow obstruction and resting hyperinflation in patients with COPD. Chest. 2006;129:509-517.

43. Terzano C, Petroianni A, Conti V, et al. Rational timing of combination therapy with tiotropium and formoterol in moderate and severe COPD. Resp Med. 2008;102:1701-1707.

44. Cazzola M, Tashkin DP. Combination of formoterol and tiotropium in the treatment of COPD: effects on lung function. COPD. 2009; 6:404-415.

45. Richter K, Stenglein S, Mucke M, et al. Onset and duration of action of formoterol and tiotropium in patients with moderate to severe COPD. Respiration. 2006;73:414-419.

46. Rabe KF, Timmer W, Sagkriotis A, Viel K. Comparison of a combination of tiotropium plus formoterol to salmeterol plus fluticasone in moderate COPD. Chest. 2008;134:255-262.

47. Rossi A, Khirani S, Cazzola M. Long-acting $\beta$-agonists (LABA) in chronic obstructive pulmonary disease: efficacy and safety. Int J Chron Obstruct Pulmon Dis. 2008;3:521-529.

48. Qaseem A, Snow V, Shekelle P, et al. Diagnosis and management of stable chronic obstructive pulmonary disease: a clinical practice guideline from the American College of Physicians. Ann Intern Med. 2007; 147:633-638.

49. Tashkin DP, Celli B, Senn S, et al. A 4-year trial of tiotropium in chronic obstructive pulmonary disease. $N$ Engl J Med. 2008;359:1543-1554.

50. Niewoehner DE, Rice K, Cote C, et al. Prevention of exacerbations of chronic obstructive pulmonary disease with tiotropium, a oncedaily inhaled anticholinergic bronchodilator. Ann Int Med. 2005;143: 317-326.
International Journal of COPD

\section{Publish your work in this journal}

The International Journal of COPD is an international, peer-reviewed journal of therapeutics and pharmacology focusing on concise rapid reporting of clinical studies and reviews in COPD. Special focus is given to the pathophysiological processes underlying the disease, intervention programs, patient focused education, and self management protocols.

\section{Dovepress}

This journal is indexed on PubMed Central, MedLine and CAS. The manuscript management system is completely online and includes a very quick and fair peer-review system, which is all easy to use. Visit http://www.dovepress.com/testimonials.php to read real quotes from published authors. 